\title{
HIV-infected women of Burkina Faso: a "reservoir" of mycoplasma infection
}

\author{
Florencia Djigma $^{1,2}$, Charlemagne Ouedraogo ${ }^{1,2}$, Tani Sagna ${ }^{1,2}$, Djeneba Ouermi ${ }^{1,2}$, Korotini $^{1,2}$ \\ Sanogo $^{1}$, Cyrille Bisseye ${ }^{1,2}$, Abdoulaye Kabre $^{1}$, Virginio Pietra ${ }^{1}$, Jacques Simpore ${ }^{1,2,3}$, Jean-Baptiste \\ Nikiema ${ }^{1,2}$, Salvatore Musumeci ${ }^{4}$
}

${ }^{1}$ Centre de Recherche Biomoléculaire Pietro Annigoni CERBA/LABIOGENE, Centre Medical St Camille, 01 BP 364 Ouagadougou 01, Burkina Faso

${ }^{2}$ University of Ouagadougou, 03 BP 7021 Ouagadougou 03, Burkina Faso

${ }^{3}$ Camillian Task Force, Piazza della Maddalena, 53 - Roma, Italy

${ }^{4}$ Department of Chemical Sciences, University of Catania and Institute of Biomolecular Chemistry, CNR, Catania, Italy

\begin{abstract}
Introduction: The objective of this work was to assess the prevalence of bacterial vaginosis (BV) and genital mycoplasma colonization in 251 HIV-positive compared to 200 HIV-negative women at the Maternal and Child Health (MCH) service of Saint Camille Medical Center Ouagadougou (Burkina Faso).

Methodology: After revealing the cervix with a speculum, we collected swabs of vaginal discharge for the detection of pathogenic bacteria.

Results: Among HIV-positive and HIV-negative women, we identified respectively: Mycoplasma hominis (16.7\% versus 5.5\%); Ureaplasma urealyticum (16.3\% versus $0.0 \%)$; co-infection $M$. hominis with $U$. urealyticum $(13.14 \%$ versus $0.0 \%)$; Candida albicans $(21.11 \%$ versus $41.5 \%)$; E. coli $(9.96 \%$ versus $4.0 \%)$; and the presence of abundant vaginal discharge $(27.5 \%$ versus $5.0 \%)$ respectively. The Nugent's score, utilized for the diagnosis of BV, was significantly higher in HIV-positive women $(\mathrm{p}<0.001)$ associated with poor vaginal hygiene practices $(\mathrm{p}<0.01)$ and no use of condoms $(\mathrm{p}<0.01)$. Enterobacter, Klebsiella pneumonia, Klebsiella oxitocica, Staphylococcus epidermidis and Staphylococcus aureus, Streptococcus agalactiae, Trichomonas vaginalis, and Gardnerella vaginalis were also isolated, but in a low prevalence ranging from $0 \%$ to $5 \%$.

Conclusion: These results demonstrate that the HIV-positive women of Burkina Faso are frequently affected by BV and represent a reservoir for mycoplasma infection. Since these germs can lead to sterility and premature delivery, it is important to develop a policy of screening.
\end{abstract}

Key words: Mycoplasma hominis; Ureaplasma urealyticum; bacterial vaginosis; HIV; Burkina Faso

J Infect Dev Ctries 2011; 5(3):176-181.

(Received 17 February 2010 - Accepted 08 September 2010)

Copyright $\odot 2011$ Djigma et al. This is an open-access article distributed under the Creative Commons Attribution License, which permits unrestricted use, distribution, and reproduction in any medium, provided the original work is properly cited.

\section{Introduction}

Bacterial vaginosis (BV) is a poly-microbial syndrome characterised by a change in vaginal flora from a dominant population of Gram-positive lactobacilli to a gradual or total substitution with anaerobes such as Gardnerella vaginalis, Prevotella, Bacteroides and with other bacteria including Mycoplasma and Ureaplasma species, when they are found in large quantity (greater than or equal to $\geq 10^{4} \mathrm{UCC} / \mathrm{ml}$ ) [1]. BV is frequently encountered in women attending sexually transmitted infection (STI) and genitourinary medicine (GUM) or other reproductive health clinics (RHC). It has been reported that BV is also associated with poor pregnancy outcomes such as preterm delivery [2]; moreover, several studies have now reported associations between $\mathrm{BV}$ and HIV infection $[3,4,5]$. BV appears to be particularly common in sub-Saharan Africa, where HIV infection is endemic, and it has been reported at high prevalence rates (20-49\%) among women presenting with vaginal discharge to STI clinics $[6,7,8]$. These rates are very much higher than those reported in industrialised countries [9,10]. The reasons for these differences could be the poor hygienic conditions and limited use of condoms in resource-poor countries. However, it could also depend on the different case definitions for BV, since little is known of the pattern of vaginal microflora associated with $\mathrm{BV}$ in Africa. In fact, the study of vaginal micro-flora is an important step in understanding the pattern of flora associated with $\mathrm{BV}$ in areas such as sub-Saharan regions, where HIV infection is endemic. It is not clear whether $\mathrm{HIV}$ infection predisposes to the BV, or if changes to the vaginal flora caused by BV enhance HIV 
acquisition as previously suggested [4]. In addition, hygiene habits such as vaginal douching or menstrual hygiene practices may be important factors that influence the composition of vaginal flora [11], but at the moment little data are available from Burkina Faso populations.

The present study reports the prevalence of BV and vaginal mycoplasma colonization among HIVpositive and -negative women seeking gynaecological assistance at the Centre Medical San Camille (CMSC) of Ouagadougou, Burkina Faso. We also investigated vaginal hygiene practices, use of condoms, and the associations with HIV serostatus in these patients.

\section{Methodology}

Study population and sample collection

From February to July 2009, a total of 251 HIV-positive women and $200 \mathrm{HIV}$-negative women were enrolled in the study. None of these women were pregnant. The median age of these patients was 33.0 years (range $28-44$ ) and 35.0 years (range 27-45) respectively.

\section{Gynaecological screening}

A standardised questionnaire screened sociodemographic characteristics and reproductive and sexual history, including also the number of different sexual partners and condom use. Hygiene sexual practices including gynaecological visits, vaginal smears, and number of STIs were also noted. Women underwent genital examination during which vaginal and cervical swabs were collected. After highlighting the cervix with the speculum, two swabs of vaginal discharge in the uterine cervix were obtained for microscopic observation. The first swab of vaginal discharge was spread on two slides: one slide for fresh observation and the other slide heat fixed, Gramstained, and examined for vaginal flora categories using the Nugent's method [12].

Scores between 0 and 3 represented normal vaginal flora, while scores between 4 and 6 indicated intermediate vaginal flora, and scores between 7 and 10 were considered diagnostic for BV.

The second vaginal smear swab was immersed in sterile water and used for sowing in the MYCOPLASMA System Plus kit (Liofilchem Diagnostici, Roseto degli Abruzzi, Italy). Part of the second swab was seeded onto three mediums to detect different pathogens: Sabouraud for the detection of yeast (Candida albicans); Muller Hinton for research not requiring germs (Escherichia coli, Staphilococcus SPP, Klebsiella pneumoniae, Enterobacter spp); and chocolate agar
+ polyvitex (PVX) for the detection of bacteria (Streptococcus spp, Nesseria gonorheae).

After twenty-four hours at $37^{\circ} \mathrm{C}$, the colonies were used for identification on mini-galleries seeking their biochemical characteristics (mobility, urea, catalase, mannitol, degradation of glucose and lactose, gas, $\mathrm{H}^{2} \mathrm{~S}$, citrate, indole).

The HIV-positive women received HAART therapy. Moreover, treatment was given to all women according to protocols protecting against all likely vaginal and cervical infections. This included a single dose of $2.0 \mathrm{~g}$ of metronidazole to cover Trichomonas vaginalis and other pathogens.

\section{Statistical methods}

Demographic and infectious diseases profiles were recorded on computer files and analyzed by standard software SPSS-10 (Statistical Package for the Social Sciences, Stanford, California, USA), and EpiInfo-6 (Centers for Disease Control and Prevention, Atlanta, Georgia, USA). We conducted the Chi 2 test and the statistical significance was set at $\mathrm{p}<0.05$.

\section{Ethical Committee}

The Ethics Committee of Saint Camille Medical Centre approved this study and each mother authorized orally the collection of swabs and accepted the treatment for vaginal infection.

\section{Results}

In total, 251 HIV-positive women and 200HIV-negative women were enrolled in the study from February to July 2009. All the women reported only one sexual partner in the last three months. Of the HIV-positive women, 69/251 (27.49\%) showed vaginal discharge versus 10/200 (5.0\%) HIV-negative women $(\mathrm{p}<0.001)$. Antibiotic use prior to attending the clinic was reported by $10 \%$ of the HIV-positive and HIVnegative women with vaginal discharge. The remaining did not use treatment for vaginal discharge. No statistical difference was found among the two groups of HIV-positive and HIVnegative women according to the number of pregnancies, abortions, frequency of intercourse, and number of different sexual partners (data not shown). Condoms were used by $165 / 251$ and 62/200 HIV-positive and HIV-negative women respectively. Hygiene sexual practices including gynaecological visit, vaginal smears, and the number of sexually transmitted infections (STIs) were frequent with 130/251 HIV-positive and 69/200 HIV-negative women. Mycoplasma hominis was identified in 42 of 251 (16.7\%), Ureaplasma 
Table 1. Prevalence of Mycoplasma hominis and Ureaplasma urealyticum in HIV-positive and HIV-negative women at CMSC, Ouagadougou.

\begin{tabular}{|l|l|l|l|}
\hline & $\mathrm{HIV}+$ & $\mathrm{HIV}-$ & $\mathrm{p}$ value \\
\hline Mycoplasma hominis & $42 / 251(16.7 \%)$ & $11 / 200(5.5 \%)$ & $<0.001$ \\
\hline Ureaplasma urealyticum & $41 / 251(16.3 \%)$ & $0 / 200(0.0 \%)$ & $<0.001$ \\
\hline Mycoplasma + Ureaplasma & $33 / 251(13.14 \%)$ & $0 / 200(0.0 \%)$ & $<0.001$ \\
\hline
\end{tabular}

urealyticum in 41 of $251(16.3 \%)$, and both microorganisms in 33 of 251 (13.14\%) HIVpositive women. Mycoplasma hominis was detected in $11 / 200 \quad(5.5 \%)$ HIV-negative women, whileUreaplasma urealyticum was not found in HIV-negative women (see Table 1).

\section{Vaginal flora cultures}

Positive isolates were found in 101 of $251 \mathrm{HIV}$ positive (40.24\%) and in 124 of 200 (62 \%) HIVnegative women. In a low percentage (ranging from 0-5\%) of HIV-positive and HIV-negative women, Enterobacter, Klebsiella pneumonia, Klebsiella oxitocica, Staphylococcus epidermidis Streptococcus agalactiae, Gardnerella vaginalis and Tricomonas vaginalis were isolated in the vaginal swabs. Candida albicans was found in $83 / 200(41.5 \%)$ and $E$. coli in $8 / 200(4.0 \%)$ of HIVnegative women versus 53/251 (21.11\%) and $25 / 200(9.96 \%)$ respectively of HIV-positive women (see Table 2).

A low prevalence of anaerobic bacteria was comparable in the two groups: Staphylococcus aureus was more frequent in HIV-negative women (5\%) (P 0.038), and Gram-positive Lactobacillus was found in HIV-negative women in only two cases.

Table 3 reports the correlations among vaginal flora, hygiene sexual practices, and use of condoms in HIV-positive and in HIV-negative women. As shown in the table 3 , the presence of mycoplasma hominis was associated with limited use of condoms $(\mathrm{p}=0.01)$ and that of ureoplasma urealyticum with poor hygienic sexual practices $(\mathrm{p}$ $=0.01)$ and scanty use of condoms $(p=0.035)$ in HIV-positive women, while the presence of staphylococcus aureus was associated with poor hygienic sexual practices $(\mathrm{p}=0.005)$ and infrequent use of condoms $(p<0.001)$ in HIV-negative women.

In Table 4, the correlation among the Nugent's score and presence of mycoplasma and ureaplasma in HIV-positive and in HIV-negative woman is shown.

In HIV-positive women, a significant concentration of mycoplasma was observed in subjects with Nugent's scores of 7-10 compared to HIV-negative women, while Ureaplasma was present prevalently in subjects with scores of 4 to 6 .

\section{Discussion}

The main objective of this study was to determine the prevalence of $\mathrm{BV}$ in Burkinabe women and to correlate the pattern of vaginal micro-flora among HIV-positive and HIV-negative women to vaginal hygiene practices and use of condoms. Using Nugent's score as the gold standard, a BV prevalence of 63/251 (25.09\%) and

Table 2. Results of vaginal flora cultures for aerobic and anaerobic bacteria as well as Trichomonas vaginalis in both HIV-positive and in HIV-negative women at CMSC.

\begin{tabular}{|l|l|l|l|}
\hline & $\mathrm{HIV}+(\mathrm{n} .251)$ & $\mathrm{HIV}-(\mathrm{n} .200)$ & $\mathrm{p}$ value \\
\hline Candida albicans & $53(21.11 \%)$ & $83(41.5 \%)$ & $<0.001$ \\
\hline Escherichia coli & $25(9.96 \%)$ & $8(4.0 \%)$ & 0.016 \\
\hline Lactobacillus & - & $2(1.0 \%)$ & - \\
\hline Enterobacter & $1(0.40 \%)$ & $2(1.0 \%)$ & $0.843(\mathrm{NS})$ \\
\hline Klebsiella pneumoniae & $2(0.80 \%)$ & $5(2.5 \%)$ & $0.285(\mathrm{NS})$ \\
\hline Klebsiella oxitoca & $1(0.40 \%)$ & $1(1.0 \%)$ & $0.843(\mathrm{NS})$ \\
\hline Staphylococcus aureus & $4(1.59 \%)$ & $10(5.0 \%)$ & 0.038 \\
\hline Staphylococcus epidermidis & $1(0.40 \%)$ & - & - \\
\hline Streptococcus agalactiae & $4(1.93 \%)$ & $4(2.0 \%)$ & $0.739(\mathrm{NS})$ \\
\hline Gardnerella vaginalis & $10(3.98 \%)$ & $9(4.50 \%)$ & $0.786(\mathrm{NS})$ \\
\hline Trichomomas vaginalis & $2(0.80 \%)$ & $5(2.5 \%)$ & $0.285(\mathrm{NS})$ \\
\hline
\end{tabular}




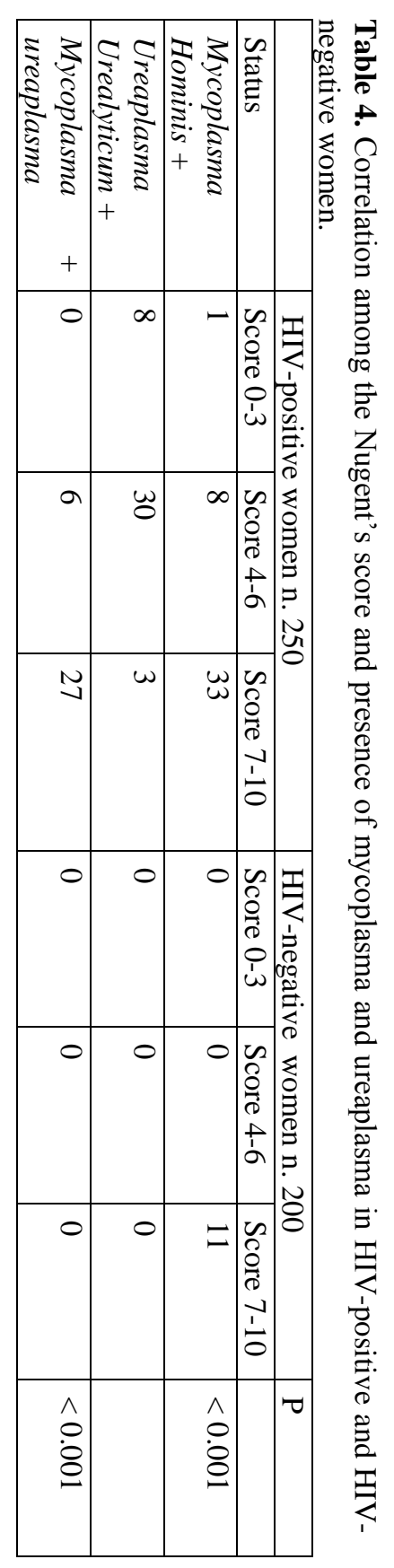

\begin{tabular}{|c|c|c|c|c|c|c|c|c|c|c|}
\hline 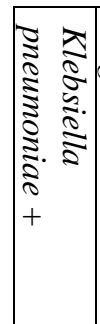 & 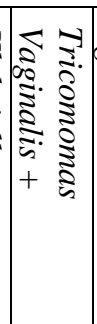 & 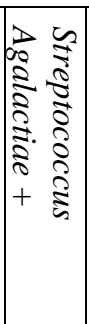 & 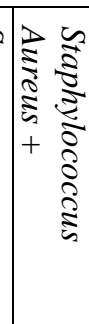 & 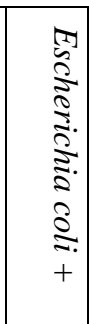 & 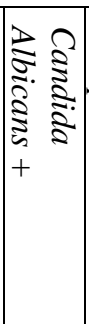 & 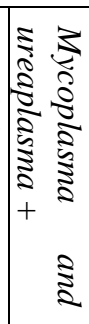 & 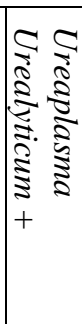 & 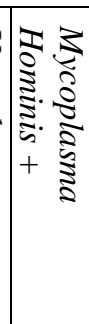 & 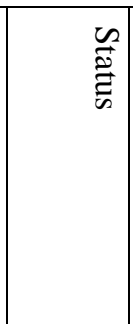 & \\
\hline 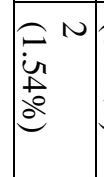 & 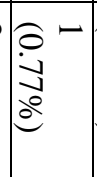 & $\begin{array}{l}0 \\
\dot{0} \\
-3 \\
e^{-}\end{array}$ & ' & 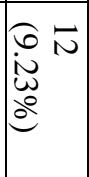 & 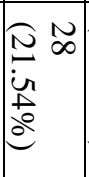 & 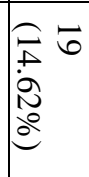 & 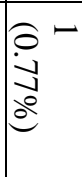 & 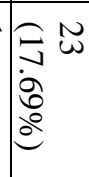 & 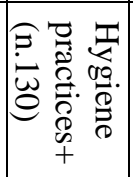 & \\
\hline 1 & $\begin{array}{l}0 \\
0 \\
\infty \\
w \\
j^{9}\end{array}$ & 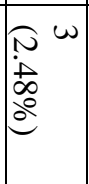 & $\begin{array}{l}\stackrel{+}{\omega} \\
\stackrel{\omega}{\omega} \\
e^{Q}\end{array}$ & 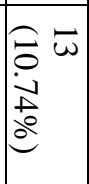 & 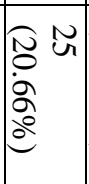 & $\begin{array}{l}\vec{E} \\
\vec{y} \\
\vec{d} \\
d\end{array}$ & 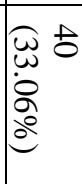 & 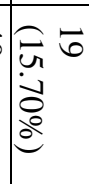 & 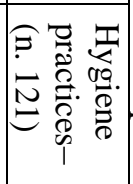 & 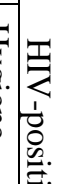 \\
\hline I & I & $\begin{array}{l}\dot{0} \\
\dot{u} \\
\dot{a}\end{array}$ & ' & $\begin{array}{l}\circ \\
\dot{\alpha} \\
\dot{0}\end{array}$ & $\begin{array}{l}0 \\
\dot{\infty} \\
\dot{q} \\
\dot{u}\end{array}$ & $\begin{array}{l}\circ \\
\stackrel{\Delta}{\sigma} \\
\end{array}$ & $\hat{O}$ & $\dot{\vec{\omega}}$ & $\nabla$ & 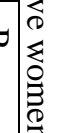 \\
\hline $\mid \begin{array}{l}\hat{O} \\
\dot{0} \\
\dot{0} \\
\hat{a}\end{array}$ & & $\begin{array}{l}\hat{0} \\
\dot{0} \\
\dot{a} \\
\dot{a}\end{array}$ & & $\mid \begin{array}{ll}\omega & u \\
0 \\
w \\
a^{a}\end{array}$ & 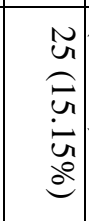 & $\overbrace{}^{\infty} \omega$ & $\overrightarrow{\stackrel{N}{a}}^{N}$ & $\begin{array}{l}\hat{\partial} 0 \\
\dot{\hat{\theta}} \\
\dot{\alpha}\end{array}$ & 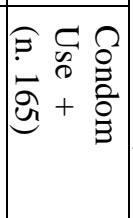 & 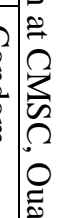 \\
\hline 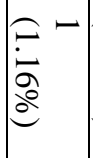 & $\mid \begin{array}{l}\tilde{N}^{N} \\
\tilde{N} \\
\mathfrak{d}^{a}\end{array}$ & 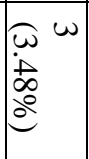 & 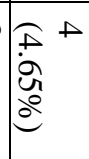 & 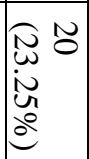 & 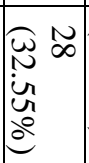 & 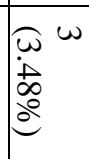 & 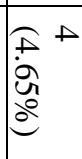 & $\begin{array}{l}\omega \\
\underset{N}{N} \\
\dot{N} \\
e^{q}\end{array}$ & 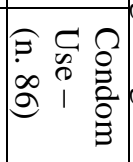 & 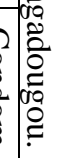 \\
\hline I & I & 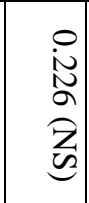 & & $\begin{array}{l}\hat{O} \\
\dot{0}\end{array}$ & $\begin{array}{l}\hat{ᄋ} \\
\dot{8}\end{array}$ & $\begin{array}{l}\stackrel{0}{0} \\
\dot{0} \\
\infty \\
z \\
0\end{array}$ & $\begin{array}{l}\stackrel{0}{0} \\
\dot{u} \\
u\end{array}$ & $\hat{O}$ & $\nabla$ & \\
\hline 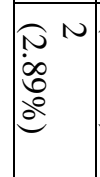 & $\underset{e^{a}}{\vec{a}}$ & 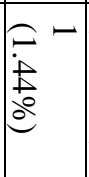 & $\begin{array}{l}\tilde{J}^{\infty} \\
\dot{i} \\
j^{9}\end{array}$ & 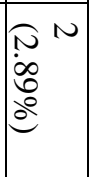 & 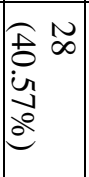 & & & 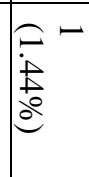 & 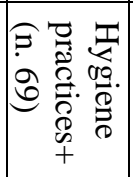 & \\
\hline 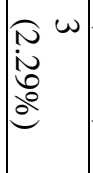 & 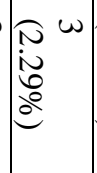 & 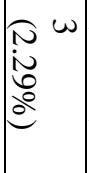 & 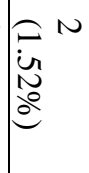 & $\begin{array}{l}\text { I } \\
\dot{i n} \\
\infty \\
a \\
a\end{array}$ & 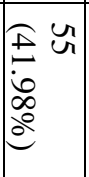 & & & $\begin{array}{l}\vec{j} \\
\dot{\omega} \\
\dot{\omega} \\
\dot{a}\end{array}$ & 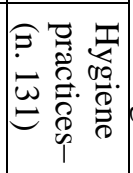 & 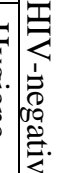 \\
\hline 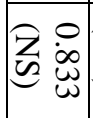 & $\left(\begin{array}{ll}Z & 0 \\
Z & \infty \\
0 & 0 \\
0\end{array}\right.$ & \begin{tabular}{ll}
$z$ & 0 \\
\hdashline & 0 \\
0 & 0 \\
+
\end{tabular} & 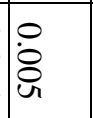 & $\begin{array}{ll}Z & 0 \\
Z & \infty \\
0 & 0 \\
0\end{array}$ & 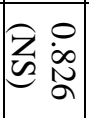 & & & $\begin{array}{ll}Z & 0 \\
2 & 0 \\
0\end{array}$ & $\nabla$ & ○ \\
\hline $\mid$ & $\mid \begin{array}{ll}\omega_{0} & N \\
i \\
N \\
e^{a}\end{array}$ & $\begin{array}{l}\frac{a}{a} \\
\frac{a}{2}\end{array}$ & 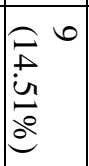 & $\begin{array}{l}a \\
\frac{a}{a} \\
a\end{array}$ & 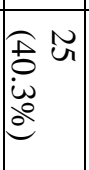 & & & 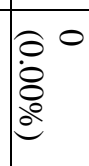 & 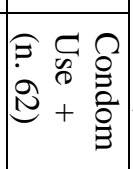 & $\left\{\begin{array}{l}3 \\
\Omega \\
\Omega \\
\Omega \\
\Omega\end{array}\right.$ \\
\hline 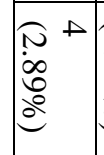 & $\mid \begin{array}{l}\hat{e}^{N} \\
\vec{e}^{a} \\
a^{a}\end{array}$ & 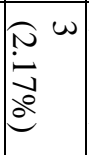 & $\begin{array}{l}\hat{a}- \\
\mathbf{N} \\
\text { a }\end{array}$ & 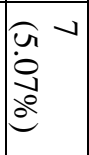 & 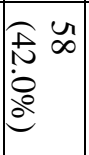 & & & $\begin{array}{l}\vec{i} \\
\vec{b} \\
\vec{d} \\
0\end{array}$ & 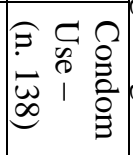 & 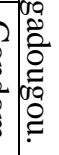 \\
\hline 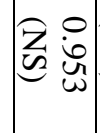 & 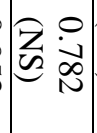 & 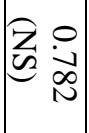 & $\begin{array}{l}\hat{ᄋ} \\
\dot{\delta}\end{array}$ & 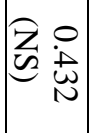 & 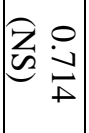 & & & & $\nabla$ & \\
\hline
\end{tabular}


of 11/200 (5.5\%) in HIV-positive and in HIVnegative women respectively was found.

A previous study in Burkina Faso [7] reported $20-23 \%$ in STI clinics, but this is the first study to report data on HIV-positive women. The reason for higher BV in HIV-positive women in the African population is not known, but the correlation between HIV serostatus and lifestyle practice such as vaginal douching and no use of condoms could explain this increased prevalence of BV $[13,14,15]$. However, this association may be influenced by the level of education and other socio-economic and behavioural factors which must be taken into consideration. In fact, it is not clear whether the high prevalence of mycoplasma in HIV-positive women could be attributed to vaginal hygiene practices, such as douching before and after sex, the nature of the douching compound used, the source of water, or menstrual sanitary protection. The difference in HIV-negative women perhaps owes to the fact that a very large proportion of HIVnegative women respect these practices. Moreover, it is important to consider that in addition to having poor hygiene practices, the HIV-positive women are affected by HIV-associated immunodeficiency, which predisposes the vagina to bacterial colonization and to mycoplasma colonization. In fact, an association between BV and HIV, also possibly influenced by poor vaginal hygiene, has been reported in several studies [3,5]. In our study, a significant association has been found among these factors.

We did not find an association between HIV, $\mathrm{BV}$ and colonization of lactobacillus species among either HIV-positive or HIV-negative women. The reason for this low colonization is not clear since lactobacillus play an important role in the maintenance of normal vaginal flora. Again, the probable explanation may be the hygienic practices of Burkinabe women.

Another observation that should be addressed is the low prevalence of $G$. vaginalis anaerobes, which are associated paradoxically to scanty vaginal/cervical colonization of lactobacillus strains. On the contrary, the absence of lactobacillus was associated with the growth of Candida spp in HIV-negative women. The presence of Candida does not influence the Nugent's score because it is not a cause of vaginosis but of infectious vaginitis. This data is also surprising because we expected that Candida should be prevalent in HIV-positive women resulting from a decline of natural immunity due to HIV. In previous studies [16,17] both $M$. hominis and Ureoplasma have been associated with BV [18], but in our study Ureoplasma was not found in HIV- negative women. This disparity with other studies may be due to the different detection protocols used. Other bacteria that have been isolated in this study, but at a very low prevalence, were not associated with the particular vaginal microflora responsible for BV. Some streptococci were found to belong to group $\mathrm{B}$, an organism which can be highly pathogenic for newborns, particularly at the time of delivery, when it is associated with neonatal sepsis and premature delivery [19]. The prevalence of streptococcus B seems in this study to be particularly low (1-3\%) compared to that reported in other parts of Africa [20], where surprisingly the high prevalence of streptococcus was not associated with disease in newborns.

\section{Conclusion}

This study confirms that in our cohort, the pattern of organisms cultured in BV of HIVpositive woman is different from that found in a corresponding population of HIV-negative woman, and therefore suggests that different vaginal flora patterns may be the major explanation for the higher prevalence of BV in African women. BV not only promotes the acquisition of HIV, but also the rate of viral shedding in genital secretion. Further studies on the public health significance of BV in this kind of setting are needed to determine future strategies for the prevention of newborn pathologies associated with maternal pathogens. Knowing that BV can lead to sterility and preterm delivery, it is important to develop BV screening and care policies as well as BV prevention programs and educational sanitary and hygiene programs to protect young women.

\section{Acknowledgements}

The authors are grateful to the staff of Saint Camille and CERBA laboratories. They are deeply grateful to the Italian Episcopal Conference (CEI) and to the RADIM House, Roma, Italy, and Doctor Luigi SPARANO for the financial support.

\section{References}

1. Hillier SL and Holmes KK (1999) Bacterial vaginosis. in Sexually Transmitted Diseases. $3^{\text {rd }}$ edition. Edited by: Holmes KK, Sparling PF, Mardh PA, Lemon SM, Stamm WA, Piot P, Wasserheit JN. McGraw-Hill, New York. pp. 563-586.

2. Carey JC and Klebanoff MA (2003) What have we learned about vaginal infections and preterm birth? Semin Perinatol 27: 212-216.

3. Royce RA, Thorp J, Granados JL, Savitz DA (1999). Bacterial vaginosis associated with HIV infection in pregnant women from North Carolina. J Acquir Immune Defic Syndr Hum Retrovirol 20: 382-386.

4. Schmid G, Markowitz L, Joesoef R, Koumans E (2000) Bacterial vaginosis and HIV infection. Sex Transm Infect 76: 3-4.

5. Sewankambo N, Gray RH, Wawer MJ, Paxton L, McNaim D, Wabwire-Mangen F, Serwadda D, Li C, 
Kiwanuka N, Hillier SL, Rabe L, Gaydos CA, Quinn TC, Konde-Lule J (1997) HIV-1 infection associated with abnormal vaginal flora morphology and bacterial vaginosis. Lancet 350: 546-550.

6. Fonck K, Kidula N, Jaoko W, Estambale B, Claeys P, Ndinya-Achola J, Kirui P, Bwayo J, Temmerman M (2000) Validity of the vaginal discharge algorithm among pregnant and non-pregnant women in Nairobi, Kenya. Sex Trans. Infect 76: 33-38.

7. Meda N, Sangaré L, Lankoandé S, Sanou PT, Compaoré PI, Catraye J, Cartoux M, Soudré RB (1997) Pattern of sexually transmitted diseases among pregnant women in Burkina Faso, west Africa: potential for a clinical management based on simple approaches. Genitourin Med 73: 188-193.

8. Walraven G, Scherf C, West B, Ekpo G, Paine K, Coleman R, Bailey R, Morison L (2001) The burden of reproductive-organ disease in rural women in The Gambia, West Africa. Lancet 357: 1161-1167.

9. Hay PE, Taylor-Robinson D, Lamont RF (1992) Diagnosis of bacterial vaginosis in a gynaecology clinic. Br J Obstet Gynaecol 99: 63-66.

10. Morris MC, Rogers PA, Kinghorn GR (2001) Is bacterial vaginosis a sexually transmitted infection? Sex Transm Infect 77: 63-68.

11. Martino JL and Vermund SH (2002) Vaginal douching: evidence for risks or benefits to women's health. Epidemiol Rev 24: 109-124.

12. Nugent RP, Krohn MA, Hillier SL (1991) Reliability of diagnosing bacterial vaginosis is improved by a standardized method of gram stain interpretation. J Clin Microbiol 29: 297-301.

13. Fonck K, Kaul R, Keli F, Bwayo JJ, Ngugi EN, Moses S, Temmerman M (2001) Sexually transmitted infections and vaginal douching in a population of female sex workers in Nairobi, Kenya. Sex Transm Infect 77: 271275.

14. Gresenguet G, Kreiss JK, Chapko MK, Hillier SL, Weiss NS (1997) HIV infection and vaginal douching in central Africa. Aids 11: 101-106.
15. Holzman C, Leventhal JM, Qiu H, Jones NM, Wang J (2001) Factors linked to bacterial vaginosis in nonpregnant women. Am J Public Health 91: 1664-1670.

16. Mardh PA, Elshibly S, Kalling I, Hellberg D (1997) Vaginal flora changes associated with Mycoplasma hominis. Am J Obstet Gynecol 176: 173-178.

17. Thorsen P, Jensen IP, Jeune B, Ebbesen N, Arpi M. Bremmelgaard A, Moller BR (1998) Few microorganisms associated with bacterial vaginosis may constitute the pathologic core: a population-based microbiologic study among 3596 pregnant women. Am J Obstet Gynecol 178: 580-587.

18. Arya OP, Tong CY, Hart CA, Pratt BC, Hughes S, Roberts P, Kirby P, Howel J, McCormick A, Goddard AD (2001) Is Mycoplasma hominis a vaginal pathogen? Sex Transm Infect 77: 58-62.

19. Regan JA, Klebanoff MA, Nugent RP, Eschenbach DA, Blackwelder WC, Lou Y, Gibbs RS, Rettig PJ, Martin DH, Edelman R (1996) Colonization with group B streptococci in pregnancy and adverse outcome: VIP Study Group. Am J Obstet Gynecol 174: 1354-1360.

20. Suara RO, Adegbola RA, Barker CJ, Secka O, Mulholland EK, Greenwood BM (1994) Carriage of Group B streptococci in pregnant Gambian mothers and their infants. J Infect Dis 170: 1316-1319.

\section{Corresponding author}

Prof. Salvatore Musumeci

Department of Chemical Sciences

University of Catania and Institute of Biomolecular Chemestry, CNR

Viale Andrea Doria n. 6, 951225

Catania, Italy

Cell: 0039-360285505; Fax 0039-0957179690

Email: smusumeci@dipchi.unict.it

Conflict of interests: No conflict of interests is declared. 